\title{
Study on EDMn-B-00 Electrode and Surfacing Process
}

\author{
Li Yang ${ }^{1, a}$, Xiangying Dang ${ }^{2, b}$, Nan $\mathrm{Ji}^{1}$, Meng $\mathrm{Li}^{1}$ \\ ${ }^{1}$ School of Mechanical and Electronic Engineering, Xuzhou Institute of Technology, Xuzhou, China \\ 221008 \\ ${ }^{2}$ School of Information and Electronic Engineering, Xuzhou Institute of Technology, Xuzhou, China \\ 221008 \\ alinlideyu@126.com, bdangpaper@163.com
}

Keywords: Surfacing, Orthogonal experiment, Work hardening; Abrasive property

\begin{abstract}
For the defect of high manganese steel surfacing electrode on manufacturability, EDMn-B-00 electrode was trial product by means of orthogonal experiment. It relays on coating to transit alloying elements. The manufacturability and usability were evaluated by chemical composition analysis, resist thermal crack test, static load work hardening test, dynamic load work hardening test and fractional wear test. The results show that activity of electrode slag is big. Melting point of electrode slag is low. Composition of deposited metal is close to that of base metal. Capability of thermal crack resist is well. Work hardening effect of deposited metal is obvious. Abrasive capability of deposited metal is superior to that of base metal.
\end{abstract}

\section{Introduction}

High manganese steel is a kind of anti-fraying steel which widely applied. It is difficult to be processed by machining because of the excellent capability of work hardening quickly. So it is always processed by means of casting or few smithing ${ }^{[1]}$. Uniformly distributed austenite in high manganese steel can be obtained by means of water toughening. It can also prevent carbide separate out. High hardness martensite can be produced when high manganese steel encounter suffering impact load or high press. Meanwhile, high plasticity austenite still exists in the internal section. The excellent impact resistance property and abrasive property benefited from the special structure which has hard surface and tough core. So high manganese steel always used in where wear seriously and impact seriously, like excavator bucket teeth and the plate for jaw cusher ${ }^{[2]}$. The brittleness phase will increase along with the improvement of hardness, which results in spalling of high manganese steel, thus, result in wear quickly. The defects of abscess and shrinkage cavity always appear in high manganese steel that produced by casting. Therefore, it needs high manganese steel surfacing electrode to repair these parts.

A new kind of surfacing electrode- EDMn-B-00 with H08A steel core and FeO-MnO slag system was trial produced by means of orthogonal experiment. Capability of resist thermal crack, static load work hardening, dynamic load work hardening and wear resist was tested. Welding procedure was also studied. These provide direction for production practice.

\section{Experiments}

Steel core and Slag System. H08A steel core and FeO-MnO slag system were used for electrode. The alloy element that deposited metal needed was transited from coating ${ }^{[3]}$. The reasons for $\mathrm{FeO}-\mathrm{MnO}$ slag system are that: complete interstitial system can formed in the conditions of various proportion, whose physical properties and process performance is stable; capability of molding and slaging off of the slag system is well under the condition of change in wide range, which provides the promise for using small current and weak standard, limiting the depth of fusion and decreasing penetration ratio.

Orthogonal Experiment. The optimizing of formula is conducted by orthogonal experiment. Experiment of three-levels and three-factors is applied on the basis of processing properties. Rockwell hardness value with $500 \mathrm{Kg}$ carries was considered as optimized target. Graphite, middle 
carbon ferromanganese and $\mathrm{K}$ value as impact factors. Range analysis was conducted after orthogonal experiment.

Chemical Composition Analysis. Metallic materials elemental analyzer was used to analysis chemical composition of deposited metal. Main elements for detecting are: C, Mn, Si, P and S.

Thermal Crack Resist Test. The shape and size of specimen are shown in Fig.1. The welding position is shown in Fig.2. S1 is restricting seam. S2 is test seam. Both of them are welded in boat form position. When S1 has been welded, S2 must be welded along the opposite direction immediately. When specimen cooled to room temperature, checked the surface crack with eyes firstly, then checked the internal crack by means of PM and measured the length of crack at last.



Fig. 1 Sample for thermal crack test

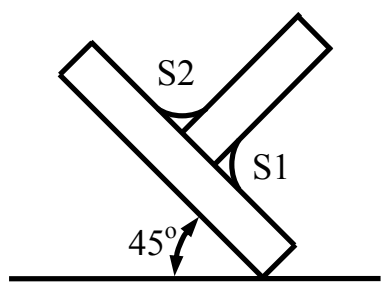

Fig. 2 Welding position

\section{Results and Analysis}

Orthogonal Experiment Results Analysis. The optimal formula after orthogonal experiment is shown in table 1 . The influence of factors to work hardening capability is discovered, graphite is significant, the next is Manganese ore and the last is $\mathrm{K}$ value.

Table 1 Optimal formula of electrode (\%)

\begin{tabular}{|c|c|c|c|c|}
\hline $\begin{array}{c}\text { Medium-carbon } \\
\text { ferromanganese }\end{array}$ & Manganese ore & Graphite & Iron oxide red & Ferro-molybdenum \\
\hline 50 & 35 & 5 & 30 & 4 \\
\hline Ferro-titanium & Cryolite & Sodium silicate modulus & $\mathrm{K}$ & \\
\hline 5 & 10 & 3 & 70 & \\
\hline
\end{tabular}

Chemical Composition of Deposited Metal Analysis. Chemical composition of deposited metal was shown in table 2. The composition is close to that of high manganese steel base metal. This promised the continuity of chemical composition between surfacing layer and base metal.

Table 2 Chemical composition of deposited metal (\%)

\begin{tabular}{|c|c|c|c|c|c|}
\hline Specimen & $\mathrm{C}$ & $\mathrm{Mn}$ & $\mathrm{Si}$ & $\mathrm{S}$ & $\mathrm{P}$ \\
\hline Deposited metal & 1.01 & 14.0 & 0.68 & 0.009 & 0.041 \\
\hline Base metal & $0.9 \sim 1.3$ & $11.0 \sim 14.0$ & $0.30 \sim 0.80$ & $\leq 0.10$ & $\leq 0.05$ \\
\hline
\end{tabular}

Thermal Crack Resist Property of Deposited Metal of Electrode. There is no crack on test seam when checked by eyes and PM. That is to say the thermal crack resist capability of this kind of electrode is well. The thermal crack inclination decreases because of the low content of S and P. The feature of low $\mathrm{S}$ decreases the thermal crack inclination greatly. The Mo element in coating could refine carbide and grain. This also contributes to the decreasing of thermal crack inclination. This kind of electrode belongs to special $\mathrm{FeO}-\mathrm{MnO}$ slag system. There is a little of slaging material in the formula. So the slag is little when welding.

Static Load Work Hardening Behavior of Deposited Metal. Curve of hardness in static load work hardening process is shown in Fig.3. The hardness of deposited metal increases when load increase. That is to say capability of work hardening is excellent. This mainly attributed to the high content of $\mathrm{C}$ and $\mathrm{Mn}$, which could enlarge the region of austenitic phase. It leads to promises deposited metal austenitize completely. Procedures of low current, weak standard and straight line carrying electrode without swing were used in welding process, so the heat input was small. Apart from all of the measures adopted above, splashing water cooling was also used to increase the 
cooling rate, these can made deposited metal gained more austenite. So the work hardening capability is excellent.

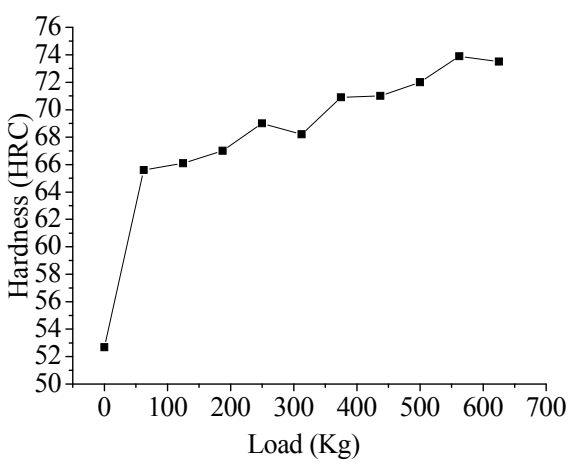

Fig. 3 Hardness curve of surface

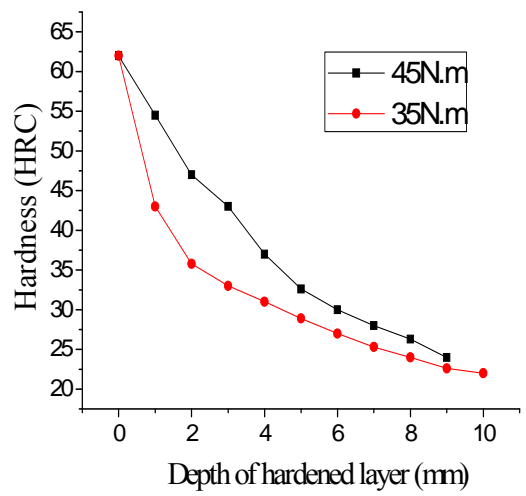

Fig. 4 Hardness curve of hardened layer

Dynamic Load Work Hardening Behavior of Deposited Metal. Curve of hardness in dynamic load work hardening is shown in Fig.4. It can be seen that hardness of deposited metal decreases with the increase of depth of hardened layer. Greater the load is adopted, slower the hardness decreases. This is because of the work hardening occurred in the plastic deformation area under dynamic load and great pressure ${ }^{[4]}$. Effect of work hardening weakened with the increase of depth in hardening layer. The core remains excellent ductility and toughness. Meanwhile, the work hardening effect under dynamic load is not extremely obvious, the main reason is that load adopted is smaller to protect sample. If large load is used, the work hardening effect must be much more obvious.

Abrasive Property of Deposited Metal. Results of fractional wear test are showed in table 3. It can be seen that abrasive capability of deposited metal is superior to high manganese steel base metal. Although the alloy element burning seriously for the strong oxidizing of slag and surrounding atmosphere, sufficient $\mathrm{C}$ and $\mathrm{Mn}$ still transited from coating. This can be seen in table 2 . They can lead to austenitize. In addition, high speed of cooling lead to high content of austenite remained. So the abrasive capability is excellent.

Table 3 Result of wear test

\begin{tabular}{|c|c|c|c|}
\hline specimen & before test [g] & after test [g] & be worn [g] \\
\hline Base metal & 49.2438 & 49.1944 & 0.0494 \\
\hline Deposited metal & 47.3468 & 47.2982 & 0.0486 \\
\hline
\end{tabular}

\section{Welding Process}

Generally, it should employ low current (60A-100A) and weak standard as far as possible to decrease penetration ratio and width of HAZ when surfacing. To guarantee the chemical composition of surfacing layer and reduce the tendency of heat crack, the minimum current is $60 \mathrm{~A}$ when electrode diameter is $3.2 \mathrm{~mm}$. The minimum current is $80 \mathrm{~A}$ when electrode diameter is $4.0 \mathrm{~mm}$. To decrease welding stress and retain more austenite, processes of short-track welding, intermittent welding, narrow-path welding and straight line carrying electrode without swing must be employed. The interlayer temperature must be cooled to room when multi-layer welding. This made the deposited metal has the same properties of base metal. Brittle martensite always emerges when high manganese steel was surfaced on carbon steel or low alloy steel. The crack in brittle zone can develop into big crack in the heavy impact, which arouses spall of surfacing layer. So austenitic stainless steel is usually used as transition layer.

Work hardening layer of base material should be grinded or removed by carbon arc gouging before welding. Therefore, proper groove should be machined by oxy-acetylene flame, then defects like crack on surface, work hardening layer and fatigue layer etc should be removed by carbon arc gouging, before surfacing on bucket teeth.

Forms of hardfacing weld bead vary according to service conditions. Continuous-single welding bend surfacing always be employed in the area of tooth tip. Cross-narrow welding bead surfacing usually be employed in rooting area. Bucket teeth used to exploit large size material should be 
surfacing along the length direction. Continue-gapless welding bead surfacing applied in the tooth tip area, while continue-gap welding bead surfacing in the root area. If granular material is exploited by bucket teeth, horizontal welding bead parallel to end line of teeth should be employed. To decrease heat accumulation to minimum, four teeth usually repaired and surfaced at the same time. Short-track welding is employed in turn.

\section{Conclusions}

1) $\mathrm{FeO}-\mathrm{MnO}$ slag system was used in electrode of EDMn-B-00. The slag has the characteristics of high activity and low melting point. Contents of $\mathrm{C}, \mathrm{Mn}$ and $\mathrm{Si}$ are $1.01 \%, 14.0 \%$ and $0.68 \%$ respectively. Contents of $\mathrm{S}$ and $\mathrm{P}$ are very low. The chemical composition of deposited metal is close to high manganese steel base metal.

2) The manufacturability and usability of EDMn-B-00 are well. Capability of thermal crack resist is excellent. Work hardening effect of deposited metal is obvious. Abrasive capability of deposited metal is superior to that of base metal.

3) The electrode is process flexibility. Weak standard in welding is advised. Straight line carrying electrode without swing should be employed. Pay attention to interlayer temperature when multi-layer welding. Every section needs to be splashed immediately followed with hammering weld bead after welding.

4) The economic benefits and effects are significant when this electrode is surfaced on high manganese steel products (like excavator bucket teeth), ordinary carbon steels and low alloy steel.

\section{Acknowledgements}

The authors acknowledge the financial support of this work from the Scientific and Technology Support Program of Jiangsu Province (BE2011048).

\section{References}

[1] L. Yang, P. Wang and J.H. Shi. Journal of Zhengzhou Textile Institute, Vol. 10 (1999) No.4, p.86.

[2] Z.D. Zhou, X. Chen and J.L. Liu. Coal Mine Machinery, Vol. 32 (2011) No.3, p.7.

[3] P. Polukhin, B. Ginberg, S. Kantenik, V. Zhadan and D. Vasilyev. Metal Process Engineering (Union of Soviet Socialist Republics 1977). P.272.

[4] Y. Wang, S.H. Si. Iron and Steel, Vol. 36 (2011) No.10, p.54. 